\title{
CLINICAL ASCARIASIS IN CHILDREN
}

\author{
BY \\ CICELY D. WILLIAMS, D.M., M.R.C.P., D.T.M. \& H.
}

The accounts of ascariasis in standard text-books appear to be inadequate to those who have had much practical acquaintance with the infestation.

Paterson (1937) states 'Children infected with ascaris appear in moderately good health.' In 'Diseases of Children' by Garrod, Batten, Thursfield and Paterson (1934), it is recorded that 'there are no clinical symptoms by which round worm can be diagnosed until the worm appears.'

The ascaris index of a population is an important indication of its sanitary advancement. In countries where ascariasis is prevalent, and in some places up to 70 per cent. of the population may be affected, it is necessary to appreciate the variety and the severity of the conditions which may be produced. It is true that many adults may harbour the worms without much obvious inconvenience. The discovery of their presence during routine examination in healthy individuals and also in hospital patients whose disease seemed to be in no way connected with the condition, has led to the firm and often dangerous belief that these parasites are almost harmless. Whatever may be the immunity developed or acquired by adults, it is certain that the health of children may be seriously undermined by these helminths, and their presence is responsible for a vast morbidity and a considerable mortality.

\section{General Considerations}

The ascaris seems to be practically world-wide in distribution. It is common in the north-east districts of London and nearer the equator it is much more common. It abounds more profusely where sanitation is primitive and where there is a low standard in matters of toilet. In a tropical climate, where children spend most of the day playing about the ground near houses, there is more chance of mass infection. Males and females are equally affected. The patients generally come from unhygienic homes, but even the most protected and carefully nurtured children may occasionally become victims. Infection may take place at any time after birth, probably from the dirty fingers of the mother or other attendant; sometimes also from the ' comforter' that is dropped about the floor. This article seems to appear with great persistence as one of the first harbingers of civilization in every unsanitated family. 
At post-mortem examinations I have twice seen an ascaris four inches long in the stomachs of babies of four months who died with the symptoms of acute enteritis. Mass infestation is, however, rare before one to three years of age. At this stage a child learns to crawl about the ground, and is in the habit of putting, unchecked, dirty fingers, dirty food and all manner of stray objects into its mouth. The ground is shared by many other children, adults and animals, nearly all with insanitary habits. Heavy ascaris infestation is most common between two and six years old. After this age children may acquire some immunity. They become less inquisitive as to taste, more selective in appetite and therefore less likely to ingest objects that are grossly contaminated with faeces and hence with ascaris ova.

Routine examination of stools may lead to the discovery of the eggs at any time after six months of age. Occasionally even repeated examinations may yield entirely negative results, but the child may proceed to vomit or pass per rectum one or two well-grown ascaris. This is particularly apt to happen when there are only a few worms present, and these may be males. It would be useful if $\mathrm{x}$-ray diagnosis could be perfected or if some more reliable cutaneous reaction could be employed, particularly in the case of small babies. At present there is no certain method of diagnosis except the discovery of ova in the stool.

\section{Signs and symptoms}

A well-marked case is so typical in appearance that the diagnosis is obvious, but the mild infestation may present great difficulties in diagnosis. The signs and symptoms depend on the age of the child and the degree of the infestation, and on whether the condition is acute or chronic. The classical signs, picking the nose and grinding the teeth, are frequently but not by any means invariably present. In a small baby the symptoms are generally those of enteritis or gastro-enteritis. The alimentary tract is more irritable than that of an older child and the worms are therefore more easily vomited or evacuated before the condition becomes chronic. The toxaemia may be severe. In an older child the symptoms may be vague and elusive. There may be mild attacks of toxaemia. Cyclical vomiting that defeats treatment may end with the appearance of one or two worms. In other cases the child fails to gain weight; he is labelled as 'intestinal indigestion,' ' malnutrition ' and ' nutritional anaemia.' Anaemia is almost always present, the haemoglobin being generally decreased to $20-60$ per cent., while the blood picture is that of a secondary anaemia with sometimes an accompanying eosinophilia. These children are also particularly subject to attacks of urticaria, asthma, bronchitis and pneumonia. Their pulmonary complaints may be due to some extent to the passage of larval forms through the lungs, and also to some toxic or allergic factors, as well as to the fact that they are exceedingly subject to intercurrent infections. Traces of albumin may be found in the urine, and it is probable that the presence of ascaris is connected with an increased incidence of pyelitis and nephritis. Many cases suffer from attacks of diarrhoea. In a chronic case the stools may contain material that is so undigested that the food is passed per rectum 
practically unaltered in appearance and only slightly more offensive in smell. These attacks of diarrhoea may alternate with obstinate constipation. During these, aperients seemed to be almost powerless. There may be acute attacks of abdominal distension, simulating an acute obstruction. The abdominal musculature seems to be so weakened with distension that it refuses to act. In many of these cases it is found beneficial to encase the child in a firmly applied spiral corset of elastoplast. This seemed to reinforce the abdominal muscles and aids digestion as well as elimination.

A well-marked case of ascariasis presents a most typical appearance. The child is from two to five years old. He is peevish, with stolid intervals. He is pot-bellied and spindle-legged, with oedema of the face, hands and feet so well marked as to suggest a nephrosis. The hair is sparse, dry and staring. In an African child the hair loses its natural curl and becomes almost straight. The skin is dry and atrophic and is subject to sores and boils. A child that should be normally pigmented becomes much paler. In an African this depigmentation may be striking.

In some patients who presented the picture of typical and profound ascariasis it was found impossible to obtain any evidence of the presence of the worms. In these cases the child's condition was so feeble that probably the worms found but poor lodging and had been eliminated during an attack of diarrhoea. Many children are reduced to a pitiable condition and may die even after all the worms have been evacuated, as their intestines become so damaged and atrophic that they lose all power of assimilating nourishment.

Various observers quote enormous numbers of ascaris being passed by one individual. Between one and two hundred are not rare in children of about four years old. Sometimes the actual mass of worms reaches a surprising proportion of the total weight.

A child eighteen months old was admitted to the Children's Hospital, Accra, weighing $16 \mathrm{lb}$. After de-worming she weighed $12 \mathrm{lb}$. and subsequently proceeded to put on weight of a more desirable sort and made a good recovery.

Complications may be many and various. The worms may cause obstruction in the nose, appendix, intestines and gall bladder. At post mortem they may be found in the bile ducts throughout the liver, accompanied by multiple liver abscesses. They may even give rise to intestinal perforation and peritonitis.

It would seem that ascaris may eventually produce some sort of immunity, hence the fact that though a small child may be made ill by the presence of one worm, yet older children and adults may harbour many without obvious inconvenience. The immunity may be comparable with that produced by the tumbu fly. Babies and new-comers to the country may be infested with these larvae, but the adult native generally escapes.

\section{Treatment}

Of all the remedies, oil of chenopodium is the safest and most effective in children. It is unsuitable for out-patient administration. If the child cannot 


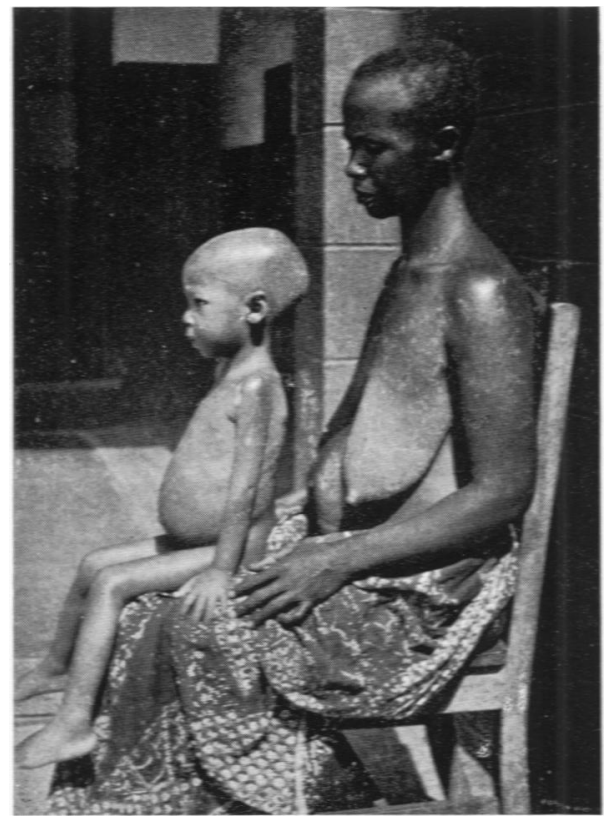

Fig. 1.-Ascariasis in an African (Ashanti) child.

Depigmentation : hair (very short in this case) dry, sparse, straight, and staring ; pendulous cheeks, distension of abdomen and oedema of extremities. The child was four years old and weighed $18 \mathrm{lb}$. She died after two months in hospital. Both parents were fullblooded Africans.

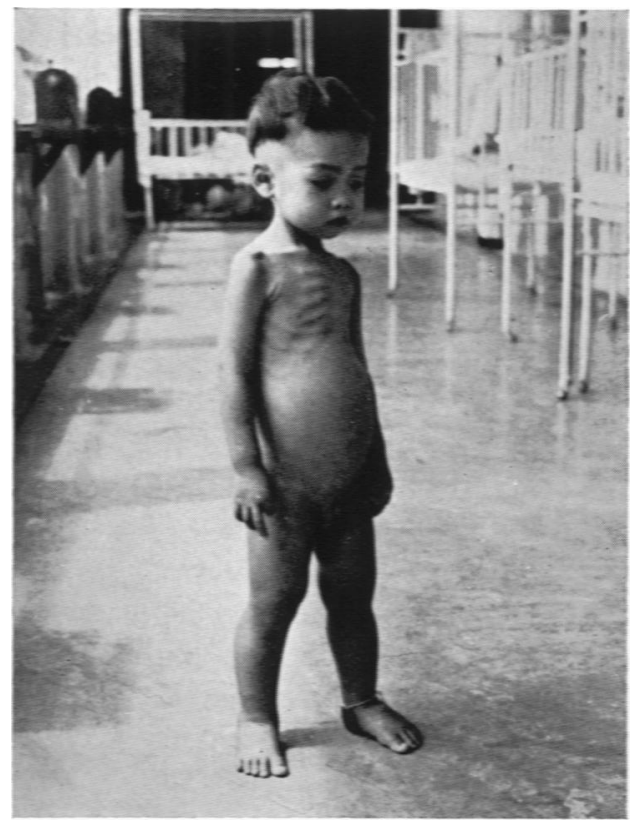

FIG. 2.-Ascariasis in a Chinese child (Singapore).

Skin is a dry, earthy colour. Hair rather thin, dry, and with a reddish colour. Chinese hair is normally jet black. Oedema of cheeks and extremities and distension of abdomen is well shown, also the stolid outlook. Child made a good recovery, after producing nearly 200 ascaris.

(Photograph by permission of the Straits Times.) 
be admitted, then santonin is undoubtedly a more suitable drug to be given at home. If, however, this has been unsatisfactory, the parents can be instructed to give aperients and a fluid diet at home ; the child is kept under observation in the hospital or dispensary for four to five hours while the chenopodium treatment is given. A fluid diet and sulphate of magnesia rather than any other aperient are important points in the treatment. The routine for an average child of three years old would be as follows :

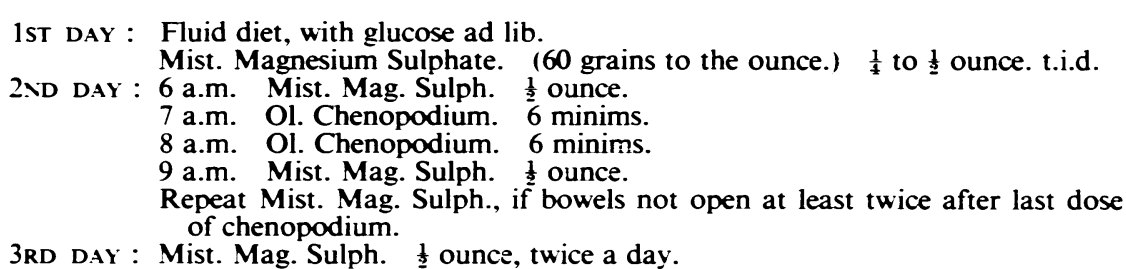

It is important to ensure that the bowels are well opened after the last dose of chenopodium. If the nursing staff observes these directions strictly large doses of chenopodium can be employed to evacuate the worms without danger of toxic effects on the child.

If the child is admitted acutely ill, it is generally better to postpone deworming until the condition is improved by general measures, or to start the treatment with a tentative dose of santonin.

When the question of immunity has been investigated it may be that some method of artificial immunization may be discovered that will prove valuable in counteracting the severe forms of toxaemia that are met with, especially in young children.

\section{Prevention}

The first step in prevention is the education of the parents. They must be taught to regard helminthiasis as a preventable disease and a worm-infested child as a disgrace-which indeed it is. Young babies should never be handled by anyone whose hands are dirty. As soon as the baby begins to crawl, he should be provided with a play pen and a mat which can be cleaned easily. Children should be taught from the earliest age not to put anything except clean food into their mouths. They must be taught to defaecate into a pot, commode or latrine, never on to the ground. The Matron, Rural Health Department, Singapore, suggests that when the parents are too poor even to provide a pot, the children can be taught to use a large leaf which is afterwards removed and buried. Children must be taught always to wash their hands before meals and after defaecation. All compounds should be provided with adequate latrines, but it must be remembered that material structures are practically useless unless they are accompanied by health education.

\section{Summary}

(1) Ascariasis causes a vast morbidity and considerable mortality in children, especially in unhygienic conditions and in the tropics. 
(2) The symptoms may include enteritis, gastro-enteritis, asthma, bronchitis, pneumonia, anaemia, oedema, nephrosis and malnutrition. They may simulate an acute abdominal emergency.

(3) Oil of chenopodium is probably the safest and most effective form of treatment.

(4) Health education is the most effective method of prevention.

I have to thank the Director of Medical Services, Malaya, for permission to publish this article.

\section{REFERENCES}

Garrod, A. E., Batten, F. E., Thursfield, H., and Paterson, D. (1934). Diseases of Children, London, 247.

Paterson, D. (1937). Sick Children, London, 512. 